\title{
Memorandum on the Present Position of Prophylaxis against Leprosy in Relation to Recent Improvement in Treatment.
}

\author{
(ABRIDGED.)
}

Sir LeONARD Rogers, C.I.E., F.R.S., I.M.s. (retd.)

Prepared for the Leprosy Conference at Manila, Fanuary, 1931 , and distributed to the members.

$\mathrm{F}$ IFTEEN years ago, in the absence of any effective treatment, even of early cases of leprosy, compulsory segregation was the only prophylactic measure in common use. The whole position requires to be reviewed in the light of the established fact that now most early cases of leprosy can be cleared of all symptoms and infectivity and prevented from going on to the more highly infective stages. If compulsory segregation inevitably leads to many of the more amenable early cases being hidden until they have reached a much more advanced and incurable stage, and have also had prolonged opportunities of infecting others before they are themselves isolated, it may do more harm than good. The question, therefore, must be fairly faced as to whether unmodified and generally applied compulsory segregation ought not to be modified to ensure that it does not result in hiding of the amenable early cases. No one has recognized more fully than I that leprosy prophylaxis must vary to a considerable extent with the local conditions, but I think the time has come when the general principles on which it should be based can be laid down in the light of our present knowledge.

The failure of compulsory segregation to stamp out or materially to reduce the prevalence of leprosy among backward races within a reasonable time.

As a result of prolonged studies of the leprosy question, I have now come to the following general conclusions regarding the prophylactic value of compulsory segregation, which I think will meet with very general acceptance. The humane Norway system of segregation, in which compulsion was only applied to a few indigent cases during the first thirty years, and only very modified compulsion used subsequently, has undoubtedly in the course of the last seventy-five years reduced leprosy to very small proportions of the numbers in 1865 , and the same system has proved of value in Sweden and Iceland under European conditions. On the other hand, among backward or uncivilised races in warm and tropical 


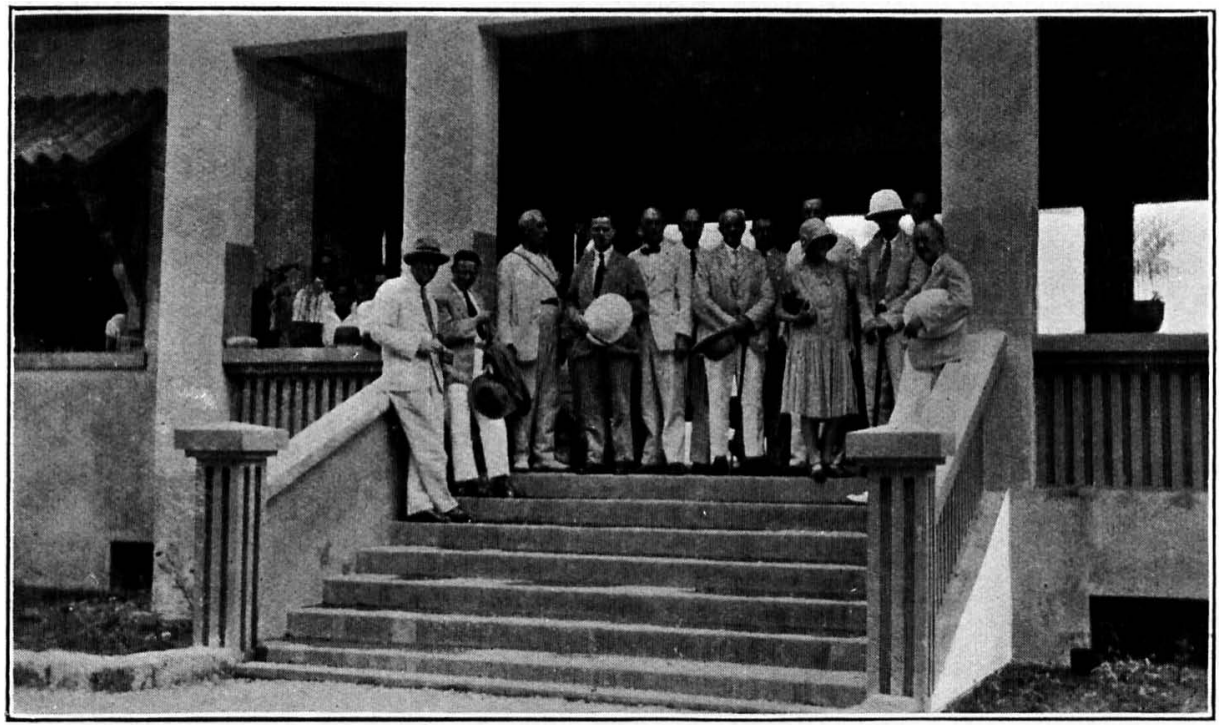

Skin Clinic, Cebu, P.I.

Conference Members from Left to right: Drs. Neff, Lampe, Maxwei.l, I.owr, Gushue-Taylor, Hulzenga, Prof. Nocht, Drs. Wade, Cole, and Tuli..

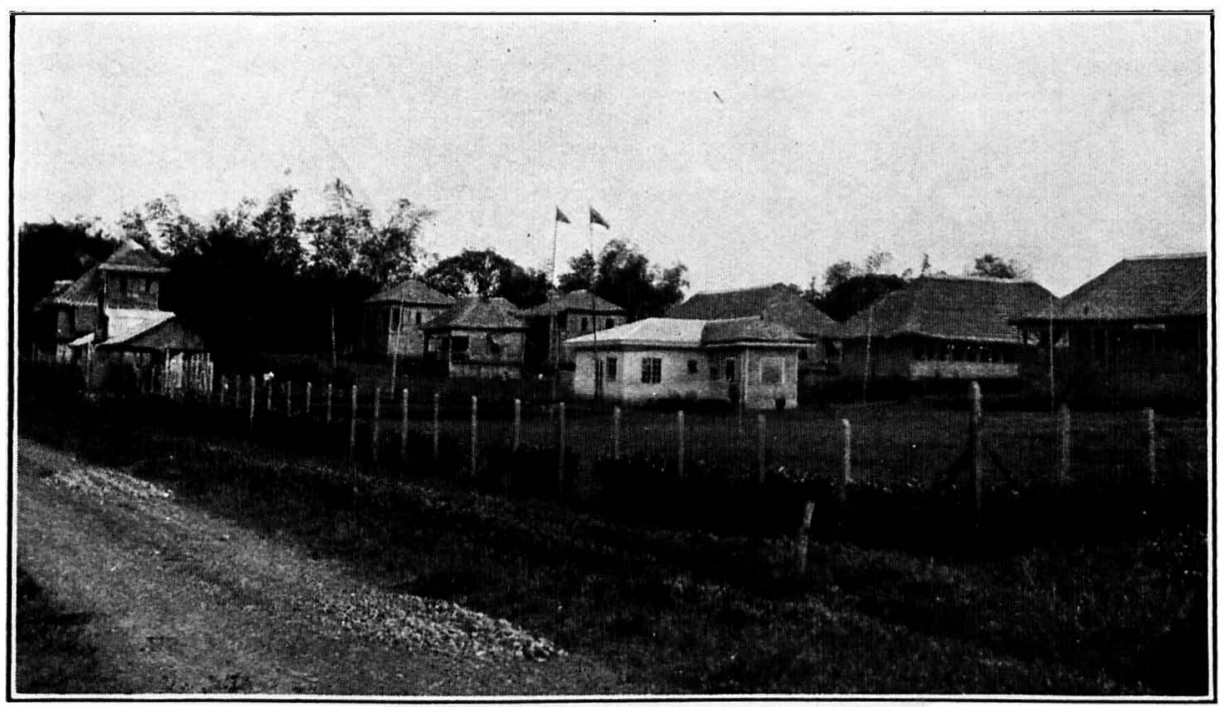

Western Visayan Skin Clinic. 
countries, no such good results have yet been obtained, even after several decades of effort. Thus, in Hawaii, where compulsion was for long the sport of politics, and has been enforced for several decades under American rule, recent reports throw grave doubt on its value, and the disease is still very prevalent. In the Philippines the great Culion experiment succeeded in removing advanced cases of leprosy from the streets of the towns, but no material reduction in the number of annual admissions has been obtained, and rigid compulsory segregation has now been modified by building leprosy hospitals for the treatment of the more amenable cases near important towns, and recently the adoption of the Indian system of treating early cases as out-patients at "skin clinics" has been introduced. In the West Indies, census figures I published in "Leprosy" appeared to indicate some success of the rigid compulsory segregation there enforced, but it has since been brought to my notice that the decline was mainly due to the repatriation of considerable numbers of Indian lepers ; so here too, there is no clear evidence of the success of the plan.

Even under much more favourable conditions in South Africa and in Australia compulsory segregation has proved very disappointing in practice. Thus in Cape Colony of South Africa compulsory segregation was first enforced in the Caledon valley as early as 1817 , and at Robben Island since 1845 , and the data from 1891 to 1907 showed a steady increase in the numbers isolated owing to the discovery of new cases. Recently more efficient segregation has been enforced, and some decrease in the number of European sufferers appears to have taken place, but none apparently among the native races, such as the Basuto, for example, where the latest report shows an increase in the numbers isolated at very great cost. It is only fair to state that owing to paucity of medical officers and difficulties of communication the problem is very difficult in Basutoland, although not more so than in tropical African colonies such as Nigeria, but the fact remains that the very severe tax on the revenues entailed by the compulsory measures has not yet been justified in Basutoland by any definite diminution of the disease. In New South Wales, where over $£ 2,000$ per head is spent annually on each segregated case, or sufficient to allow of 1,600 lepers to be treated for a year with the efficient form of sodium hydnocarpate known as alepol, some reduction in the number of Europeans infected appears to have been obtained according to Dr. Cook, but the same authority 
states that the compulsory methods have failed to reduce leprosy in the neighbouring state of Queensland.

Compulsory segregation impracticable for 99 per cent. of the world's lepers.

If compulsory segregation had been proved to be an effective method of stamping out leprosy it would still be of very little use in solving the leprosy problem as a whole, for the simple reason that it is quite impossible to carry it out for administrative and financial reasons in the areas of the greatest number of cases in India, China, and tropical Africa. Over two decades ago, Dr. Heiser estimated the world's lepers at $2,000,000$, at a time when the wide prevalence in Africa was not known. More recently, as the result of three years' study of the literature, I estimated them as not less than $3,000,000$. Since then, the leprosy surveys of Dr. Muir, in India, recently confirmed in British Guiana, by Dr. Rose, showed that for each typical advanced case, such as alone are enumerated under the compulsory segregation system, there are anything from two to ten early cases in existence, so the world's lepers may very easily number $10,000,000$. For the sake of my argument I will place the number at the very conservative estimate of $5,000,000$.

I have made out a table of the numbers recorded as being segregated at the present time in the principal countries where that measure is in force, including the data in the valuable 1930 Report of the Secretary of the League of Nations Leprosy Commission; the number comes in round numbers to 35,000 . To this may be added nearly 8,000 isolated in Indian leper asylums under a voluntary system, apart from a very few indigents, although many of them are old uninfective crippled nerve cases, whose isolation is only of humanitarian value, and does nothing to reduce leprosy infections, which will bring the number up to 43,000 . The fullest allowance for small numbers isolated in other countries with comparatively few lepers could not make the total segregations under the old system over 50,000 - just 1 per cent. of the world's lepers.

\section{Results of modern treatment.}

It is now very generally agreed that the modern treatment is far more effective than former ones, and also that not more than 10 to 20 per cent. of the advanced cases, which form the vast proportion of cases in leper asylums under the compulsory system, can be apparently cleared up by prolonged treatment as at Culion colony, and it is still doubtful 
as to how many of them relapse. Dr. Wayson has recently come to the conclusion that the last of the leprosy bacilli are rarely, if ever, eliminated from the system by the treatment in the advanced cases met with in the Hawaii leprosy institutions under the compulsory system. The same is true of tuberculosis, but the sanitorium treatment of early cases is not, on that account, considered to be useless. Under the same system in South Africa, only two years ago, the asylum medical authorities were very sceptical regarding the value of the treatment, but the latest reports record 10 to 20 per cent. of apparent recoveries.

The results in early cases are very different as shown in a table I published in 1927 (Proc. Royal Soc. Med., Vol. xx, April) with apparent recovery in 41 of $\mathrm{my}$ Calcutta Clinic cases, and 31 per cent. in Muir's continuation of my work there. At the Honolulu Hospital, among 486 cases treated during five years and reported on by $\mathrm{H}$. M. Neil, only 8 per cent. of advanced cases, but 38 per cent. of moderately advanced ones, and no less than 64 per cent. of 45 early ones were discharged on parole as apparently recovered. Other figures might be quoted, but these will suffice to establish the generally admitted fact that good results in a large proportion of cases are only to be expected when they are discovered and treated efficiently in an early stage of the disease, and the treatment in the class of cases met with under the compulsory segregation system is not sufficiently good at present to enable their treatment alone to solve the leprosy problem. The problem, therefore, will only be solved under some system which enables the great majority of the cases to be discovered and treated regularly in quite an early stage of the disease. About 100 medical men are trained yearly in India in the modern treatment of leprosy, surveys are carried out in areas where leprosy is most prevalent, and dispensaries opened for treatment, to each of which usually 200 to 300 patients come from a wide circle. Propaganda work precedes the surveys, and in these ways a very large total of the early most amenable cases of leprosy are being treated all over India, which must prevent many of them going on to the infectious stage, and thus in time bring about a material reduction in the incidence of the disease. The cost per case is very small compared with compulsory segregation. The adoption of "skin clinics" in the Philippines for the out-patient treatment of early lepers is an important extension of the Indian system. 
Voluntary colonies for the isolation and treatment of lepers in Britush tropical possessions.

It is only during the last decade or two that it has become evident that vast areas of tropical Africa have leprosy rates of several times that of India. This constitutes the most serious and difficult leprosy problem in the world to the solution of which the British Empire Leprosy Relief Association is devoting most of its limited funds. Already there are scores of clinics and small leprosy settlements treating very many cases with the help of numerous missionary medical men and women in the British African colonies; several of the most important of these now have wholetime leprosy officers organising the work. How impossible compulsion is in tropical Africa, quite apart from the prohibitive cost, will be evident from the experience in the French Cameroons, where an attempt compulsorily to segregate the lepers by sending gendarmes through the villages to collect them signally failed because the cases were hidden. Yet, when cases were sent out who had improved greatly under the modern treatment they brought back numerous new voluntary patients.

Something more than clinics were found to be necessary in these areas owing to the very limited number of medical men available to staff leper dispensaries, but, fortunately, fertile land is usually obtainable for colonies, where the patients are largely self-supporting through growing their own food, and the leper colony founded by Dr. Macdonald, in South Nigeria, alone has about 1,000 lepers under treatment, with the added advantage of isolation under a voluntary and very economical plan. How successful this work has proved may be illustrated by the 1929 report of Dr. Mayer, the Nigerian expert, who records that there are now nearly 6,000 lepers under treatment in leprosy colonies and clinics under a purely voluntary and economical system. Thus within about five years, the number of sufferers now being dealt with in Nigeria alone is not far short of the total number of cases treated in settlements in India as the result of over 50 years' work. This success is entirely the result of the attraction of the improved treatment, and is a good illustration of immense advance in the possibilities of leprosy prophylaxis at the present time, as compared with the ancient compulsory segregation system alone available only about one decade ago. I am, therefore, absolutely against the introduction of compulsory segregation in any backward areas, in which it will inevitably lead to the early more 
amenable cases being hidden, with resulting throwing away of the advantages now available through improved treatment.

Where compulsory segregation already exists it should be modified to allow early bacteriologically negative cases to be treated without compulsory segregation.

My views on this point have been clearly stated in several publications during the last few years, of which the following extract from my paper in the "Practitioner," of April, 1928, will suffice as an illustration :-

"Relaxation of compulsory isolation in the case of early uninfective lepers.-In countries where much money has been expended in segregating lepers compulsorily, I do not advise that this plan should be abandoned for the present, but that it should be modified to prevent it doing great harm by preventing patients coming forward for treatment in the earlier stages."

What I do advocate is that early uninfective cases should be permitted to be treated by their medical men or at dispensaries and hospitals without being forcibly shut up with the advanced, and of ten repulsive cases in leprosy settlements.

This simple modification of compulsory laws has already been adopted in several British Colonies, such as Mauritius, and it is now being introduced into British Guiana, where the first leprosy dispensary will shortly be built at the expense of our Association as the result of the revelations of a survey proving that it is urgently required.

The periodical examination of all contacts of infective lepers and the effective treatment of the early cases thus discovered, is the only method of reducing leprosy incidence rapidly.

I now come to my last and most important point. The rapid extension of leprosy clinics and colonies on a voluntary basis is a great step in advance of the prophylactic measures available only a decade ago, but it will require many decades of unremitting work thus to reduce leprosy to small proportions. For some years past, therefore, I have advocated a further step, which is based on two important conclusions I came to as the result of my three years' study of the literature on leprosy. These are : Firstly, about 80 per cent. of new infections are derived through living in the same house with another leper, and secondly, if the cases are detected in a fairly early stage the incubation period averages about two and a half years, as in the children born at Culion, and 
in about 80 per cent. of all cases it does not exceed five years. It follows that whenever a new infective leper is discovered the first step should be to examine, if possible, all his household and intimates for early cases of leprosy, and this examination should be repeated at least every six months for five years. Theoretically about 80 per cent. of possible infections from any leper should be thus discovered in the earliest stage, when the great majority of them may be expected to clear up and prevented from going on to the more infective stages under effective modern treatment. If this plan was repeated for another five year period there would be few remaining infectious lepers, for most of the advanced nodular stages die in eight to ten years or pass on into a little infective nerve stage, so that in time the necessity for isolating lepers compulsorily would nearly disappear. Where compulsion is already in force it may serve a useful purpose for a time in enabling pressure to be made on early uninfective cases to attend regularly for treatment on pain of isolation. That is why I have always advocated its being retained for a time where already in force, although I look forward to its becoming unnecessary before very long if modified in the way I have suggested.

The plan above suggested has now been proved to be feasible and successful in Nauru Island.

Within the last few months Dr. G. W. Bray has recorded the success of the above plan in Nauru Island in Oceana, (Proc. Roy. Soc. Med. July 1930) where, following an epidemic of influenza leaving great weakness, aggravated by deficient diet, leprosy increased so rapidly that by 1926,30 per cent. of the entire small population of about 2,000 people were infected. I was consulted about this outbreak several years ago and advised frequent examinations of the whole population for early cases, with treatment of uninfective cases as out-patients. The bacteriologically positive cases were kept on one side of the island, the negative ones remained free and were treated as out-patients, but slept apart from the healthy, and all the people were examined monthly for new cases with prompt treatment of newly discovered ones. The result has been that within three years the number of cases has been reduced by 40 per cent. and Dr. Bray informs me that not a single early treated case has gone on to an advanced highly infective stage. At this rate this appalling outbreak, the worst I know of in the literature of leprosy, will be completely under control within a single decade. My plan then has already proved successful 
under the very favourable conditions obtaining at Nauru, so it is clear that the nearer this method can be worked up to in other countries the more rapid will be the control and eventual elimination of leprosy, and the principles I have laid down in this memorandum furnish a reliable method of prophylaxis based on the recent advances in treatment.

\section{Conclusion.}

I have now dealt with the principles which I believe should guide the application of our present knowledge to the great problem of reducing and eventually stamping out leprosy from any country. In view of great variations in the local conditions each country must decide for itself how far these principles are applicable to their own conditions, but personally I am convinced that the nearer any area can get to carrying into effect the foregoing principles the better the results will be. The immense stimulus given to research on leprosy by the discovery of an improved treatment will doubtless place in our hands still more effective methods before long, and at the present transitionary period it will probably be advantageous for different countries to adopt. Personally, I should welcome such an area as South Africa sticking to rigid compulsory methods, as such would furnish a valuable control to more modern methods in use elsewhere. I only hope that this memorandum, which is at least the outcome of prolonged study of the leprosy problem, will be of help in focussing the attention of the conference on some points of great practical importance. 